\title{
Effects of propofol on renal ischemia/reperfusion injury in rats
}

\author{
SHUN YANG ${ }^{1}$, WEI-PING CHOU ${ }^{2}$ and LING PEI $^{1}$ \\ ${ }^{1}$ Department of Anesthesiology, First University Hospital of China Medical University, Shenyang, Liaoning 110000; \\ ${ }^{2}$ Department of Anesthesiology, Liaoning Cancer Hospital and Institute, Shenyang, Liaoning 110042, P.R. China
}

Received April 2, 2013; Accepted May 3, 2013

DOI: $10.3892 /$ etm.2013.1305

\begin{abstract}
Renal ischemia/reperfusion injury (IRI) is a major cause of acute renal failure. The aim of this study was to investigate whether propofol pretreatment in a rat model protects kidney tissue against IRI. Thirty-two Wistar rats were equally divided into four groups: a sham-operated group, untreated renal IRI group, and low-dose $(5 \mathrm{mg} / \mathrm{kg})$ and high-dose $(10 \mathrm{mg} / \mathrm{kg}$ ) propofol-treated groups which were treated with propofol prior to the induction of IRI. The rats were subjected to renal ischemia by bilateral clamping of the pedicles for $50 \mathrm{~min}$, followed by reperfusion. The low-dose and high-dose propofol treatment groups were pretreated via femoral vein injection with a propofol suspension prior to the induction of ischemia/reperfusion. The untreated IRI group showed significantly higher serum creatinine ( $\mathrm{SCr}$ ), blood urea nitrogen (BUN), interleukin 6 (IL-6), IL-8, tumor necrosis factor- $\alpha$ (TNF- $\alpha$ ), and malondialdehyde (MDA) levels compared with the sham-operated rats. Superoxide dismutase (SOD) levels were significantly reduced following IRI; however, they significantly increased following propofol administration. Bone morphogenetic protein 2 (BMP2) levels were significantly increased in the propofol-treated groups compared with the untreated IRI group. These results suggest that propofol reduces renal oxidative injury and facilitates repair following IRI. Propofol may play a protective role by regulating BMP2 expression in renal IRI.
\end{abstract}

\section{Introduction}

Renal ischemia/reperfusion injury (IRI) is one of the underlying causes of acute renal failure $(1,2)$. Inflammation substantially contributes to the pathogenesis of IRI with a central role for certain cells, adhesion molecules and cytokines (3). Neutrophils are inflammatory cells that are potent sources of reactive oxygen species (ROS), which are extensively gener-

Correspondence to: Dr Ling Pei, Department of Anesthesiology, First University Hospital of China Medical University, 155 S. Nanjing Street, Shenyang, Liaoning 110000, P.R. China E-mail: lingpei49@vip.sina.com

Key words: propofol, ischemia/reperfusion injury, kidney, bone morphogenetic protein 2 ated during IRI and mediate cellular damage. Oxidative stress is caused by an imbalance between ROS production and antioxidant capacity. The formation of ROS and disturbances in the balance between oxidants and antioxidants play key roles in the mechanism by which renal IR causes tissue injury $(4,5)$.

Propofol (2,6-diisopropylphenol) is a venous anesthetic extensively used in clinical practice and characterized by rapid induction and quick patient recovery from its effects. In addition, propofol is widely used as a sedative for intensive care patients. Propofol has a myocardial protective effect through a range of mechanisms, including oxygen free radical scavenging (6-8), blocking of the calcium channel by inhibiting the L-type calcium channel $(9,10)$ and inhibiting neutrophil activation $(11,12)$. The myocardial protective effect of propofol has been identified by a variety of methods using an IRI model $(6-8,12,13)$. However, the potential benefits of propofol in ameliorating renal IRI and its mechanism of action remain unknown.

Bone morphogenetic protein 2 (BMP2) is a member of the multifunctional BMP family, which is part of the transforming growth factor $\beta 1$ (TGF- $\beta 1$ ) superfamily, originally identified as substances that induce bone and cartilage formation at ectopic extraskeletal sites in vivo. BMP2 in particular is heavily glycosylated and is involved in osteoblastogenesis (14). It not only plays a significant role in the regulation of cell proliferation and apoptosis, but also in the development and repair of various organs, including bone, nerve, heart and kidney $(15,16)$.

In the current study, a regional renal IRI rat model was used to determine the effects of a clinically relevant propofol concentration during the peri-ischemic period of anesthesia. After $72 \mathrm{~h}$ of reperfusion, alterations in levels of the $\mathrm{O}_{2}{ }^{-} \mathrm{scav}-$ enger superoxide dismutase (SOD) and the lipid peroxidation by-product malondialdehyde (MDA) and the involvement of BMP2 in this process were investigated to determine whether propofol has a protective effect against renal IRI that involves these parameters of redox status.

\section{Materials and methods}

Animals. Male Wistar rats were obtained from the Animal Resource Center, Shenyang Pharmaceutical University (Shenyang, China). The rats were housed in cages with free access to water and food. Thirty-two male rats weighing 180-230 g were used. The Animal Ethics Committee of Liaoning Cancer Hospital and Institute approved this study and the experiments complied with established guidelines for animal care. 
Induction of kidney IRI. Rats were anesthetized with intraperitoneal injections of chloral hydrate (Tianjin Ruijinte Chemical Co., Ltd., Tianjin, China). Using a midline abdominal incision, the two renal pedicles were clamped for $50 \mathrm{~min}$ with microaneurysm clamps. During the period of ischemia, body temperature was maintained by placing rats on a $37^{\circ} \mathrm{C}$ heating pad. Following removal of the clamps, the kidneys were inspected for $1 \mathrm{~min}$ for restoration of blood flow, as noted by a return to their original color and then the abdomen was closed. Sham-operated rats received identical surgical procedures with the exception that microaneurysm clamps were not applied. To maintain fluid balance, all rats were supplemented with $5 \mathrm{ml}$ saline administered via the femoral vein. Propofol was purchased from Qingyuan Jiabo Pharmaceutical Co. (Shenyang, China). Rats treated with propofol received identical surgical procedures with the exception that they were supplemented with $5 \mathrm{ml}$ saline containing either 5 or $10 \mathrm{mg} / \mathrm{kg}$ propofol. The administration of saline or propofol was performed immediately prior to surgery. Rats were sacrificed 3 days after reperfusion. Blood was collected and kidney tissues were divided to be either snap frozen for subsequent mRNA extraction, fixed in $2 \%$ glutaraldehyde solution for electron microscopy or fixed in $10 \%$ neutral buffered formalin for paraffin embedding.

Assessment of kidney function and oxidative stress. Serum creatinine ( $\mathrm{SCr}$ ) and blood urea nitrogen (BUN) were measured using the picric acid and diacetyl monoxime methods (17), respectively, in the Department of Biochemistry, Liaoning Cancer Hospital and Institute.

Serum levels of SOD and MDA were measured by chemical absorbance spectroscopy (18) in the Department of Biochemistry, Liaoning Cancer Hospital and Institute.

Histological examination. Kidneys embedded in paraffin were sectioned at $3 \mu \mathrm{m}$ and stained with hematoxylin and eosin (H\&E) by standard methods. Depending on the percentage of tubules in the corticomedullary junction that exhibited necrosis, loss of the brush border, cast formation or tubular dilatation, markers of tubular damage were scored from 0 to 5 (corresponding to none, $\leq 10,11-25,26-45,46-75$ and $>76 \%$, respectively) (19). Histological examination was performed by two blinded observers. At least ten high-power fields (HPFs; magnification, $\mathrm{x} 200$ ) per section for each sample were examined.

Electron microscopy. Following perfusion, kidneys were excised and immersed in fresh fixative $(2.5 \%$ glutaraldehyde in $0.1 \mathrm{M}$ sodium cacodylate buffer, $\mathrm{pH} 7.4$ ) for $16 \mathrm{~h}$ at $4^{\circ} \mathrm{C}$. For morphological studies, the tissue blocks were post-fixed with $1 \%$ osmium tetroxide and $0.8 \%$ potassium ferricyanide in $0.1 \mathrm{M}$ cacodylate buffer, treated with aqueous $1 \%$ uranyl acetate, dehydrated in a graded ethanol series and embedded in PolyBed epoxy resin. Thin sections were cut, collected on $200-\mu \mathrm{m}$ mesh copper/rhodium grids, stained with sodium acetate and lead citrate and then observed at $60 \mathrm{kV}$ with a transmission electron microscope (Hitachi, Tokyo, Japan).

RNA extraction and quantitative polymerase chain reaction (PCR). Total RNA was isolated from renal tissue using TRIzol
(Invitrogen Life Technologies, Carlsbad, CA, USA). Equal amounts of RNA, measured by sfpectrophotometry and an RNA gel, were used for first-strand cDNA synthesis with Superscript II (Invitrogen Life Technologies) in a $20-\mu 1$ reaction. The cDNA product $(1 \mu \mathrm{l})$ was then subjected to reverse transcription-PCR(RT-PCR) with Taq polymerase (Boehringer Mannheim GmbH, Mannheim, Germany). Quantitative RT-PCR was performed using a Light Cycler system (Roche Diagnostics, Mannheim, Germany) and 2X SYBR Premix Ex Taq (Takara Bio Inc., Shiga, Japan) was used to detect PCR products. The comparative cycle threshold $(\mathrm{Ct})$ method $\left(2^{-\Delta \Delta C t}\right)$ was used to analyze relative changes in gene expression. $\beta$-actin (Actb) was used to normalize gene expression. The primer sequences were as follows: BMP-2, sense: 5'-ACGATGCCGCCATTTGTG-3' and antisense: 5'-CGC CTCGCCTTCTTCAGT-3', with the size of the PCR product being 349 bp; Actb, sense: 5'-GCCAACCGTGAAAAGATG-3' and antisense: 5'-CCAGGATAGAGCCACCAAT-3', with the size of the PCR producting being $701 \mathrm{bp}$.

Kidney tissue protein extraction for cytokine measurements. Pre-chilled CelLytic MT reagent (Sigma-Aldrich, St. Louis, MO, USA) with a $1 \%$ protease inhibitor cocktail (Sigma-Aldrich) for use with mammalian tissue extracts was added to snap-frozen kidney tissue and then homogenized. The samples were incubated for $30 \mathrm{~min}$ at $4^{\circ} \mathrm{C}$ and centrifuged at $16,000 \mathrm{x} \mathrm{g}$ at $4^{\circ} \mathrm{C}$ for $15 \mathrm{~min}$ to pelletize the tissue debris. The supernatant was stored at $-70^{\circ} \mathrm{C}$. Protein concentrations were determined by a colorimetric protein assay (Bio-Rad, Hercules, CA, USA) using protein standards from Sigma-Aldrich.

Enzyme-linked immunosorbent assay (ELISA). Cytokines were measured in kidney homogenates using ELISA kits according to the manufacturer's instructions. Kits for interleukin (IL)-6, IL-8 and tumor necrosis factor (TNF)- $\alpha$ were obtained from R\&D Systems (Shanghai, China). Protein levels of cytokines were corrected for the total amounts of protein and the results were expressed in $\mathrm{pg} / \mathrm{ml}$.

Western blotting. Aliquots $(50 \mu \mathrm{g})$ of kidney homogenates were separated on $10 \%$ polyacrylamide gels (Sigma-Aldrich) and transferred to a polyvinylidene fluoride membrane (PerkinElmer, San Jose, CA, USA). The membrane was blocked overnight in Western Blocker Solution (Sigma-Aldrich), incubated with anti-BMP2 antibody (Nventa Biopharmaceuticals Corporation, San Diego, CA, USA) in Western Blocker Solution for $1 \mathrm{~h}$, washed, incubated with anti-mouse IgG conjugated with horseradish peroxidase (Sigma-Aldrich) and then washed. Positive bands were detected by chemiluminescence technology (Sigma-Aldrich) using the G:BOX gel documentation and analysis system (Syngene, Cambridge, UK). The membrane was also probed with anti-Actb antibody (Sigma-Aldrich) for Actb expression. The intensity of each band was quantified using Image J 1.32 software (National Institutes of Health, Bethesda, MD, USA).

Statistical analyses. Results are expressed as mean \pm standard deviation (SD). SPSS software (version 11.0; SPSS, Inc., Chicago, IL, USA) was used for all statistical analyses. Multiple groups were compared using one-way analysis of variance 

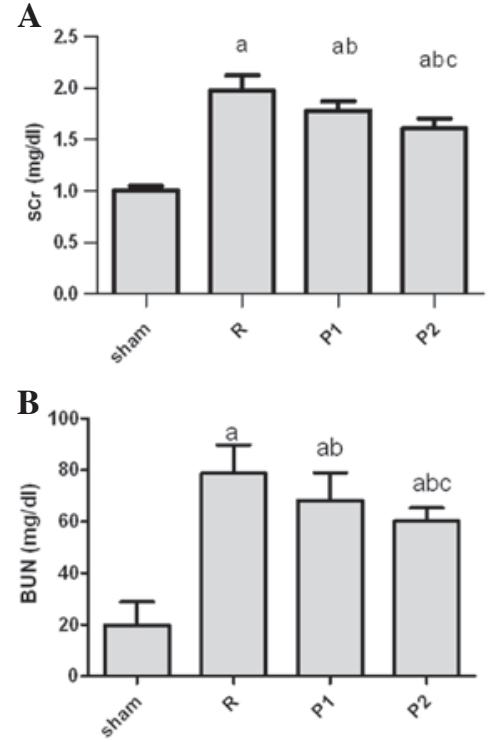

Figure 1. Propofol-treated rats were protected against renal ischemia/reperfusion injury (IRI) with significantly lower serum creatinine (SCr) and blood urea nitrogen (BUN) levels compared with untreated IRI controls following reperfusion. (A) SCr levels in the different groups. (B) Serum BUN levels in the different groups. Data are presented as mean \pm standard deviation $(\mathrm{SD})$; $\mathrm{n}=8$ per group. $\mathrm{S}$, sham-operated rats; $\mathrm{R}$, operated rats; $\mathrm{P} 1$, rats treated with $5 \mathrm{mg} / \mathrm{kg}$ propofol; $\mathrm{P} 2$, rats treated with $10 \mathrm{mg} / \mathrm{kg}$ propofol. ${ }^{\mathrm{a}} \mathrm{P}<0.05 \mathrm{vs}$. S; ${ }^{\mathrm{b}} \mathrm{P}<0.05$ vs. $\mathrm{R}$; ${ }^{\mathrm{C}} \mathrm{P}<0.05$ vs. $\mathrm{P} 1$.

(ANOVA) with a post-hoc Bonferroni correction (GraphPad Prism 5.0; GraphPad Software). $\mathrm{P}<0.05$ was considered to indicate a statistically significant difference.

\section{Results}

Rats are protected against kidney IRI by propofol injection. As shown in Fig. 1A, IRI caused kidney dysfunction in untreated rats with a peak $\mathrm{SCr}$ of $1.92 \pm 0.44 \mathrm{mg} / \mathrm{dl}$ on day 3 after IRI as compared with $0.98 \pm 0.35 \mathrm{mg} / \mathrm{dl}$ in sham-operated rats. To determine the effects of propofol on kidney IRI, rats were injected with 5 or $10 \mathrm{mg} / \mathrm{kg}$ propofol (groups P1 or P2, respectively) in the IRI model. Rats treated with propofol were protected against the effects of ischemia, exhibiting significantly lower $\mathrm{SCr}$ and BUN levels than untreated rats. By contrast, there was an increase in SCr and BUN levels in rats treated with propofol on day 3 , compared with sham rats (Fig. 1). The SCr and BUN levels in the P2 group were lower compared with those of the P1 group (Fig. 1).

The functional data correlated with histological kidney tubular damage. Severe tubular damage was observed in untreated IRI rats with no propofol treatment, as shown by widespread tubular necrosis, loss of the brush border, cast formation and tubular dilatation at the corticomedullary junction, whereas IRI rats with propofol treatment demonstrated significantly less tubular damage (Fig. 2A). Sham-operated rats incurred no tubular injury. A blind review of specimens from untreated IRI rats revealed greater tubular injury in their kidneys. The mean histological score for the kidneys of the propofol-treated $(10 \mathrm{mg} / \mathrm{kg})$ rats was $32.8 \pm 0.6 \%$ compared with $85.3 \pm 6.1 \%$ $(\mathrm{P}<0.01$; Fig. 2B) for the untreated IRI control. Tubular injury was attenuated as the propofol dosage increased (Fig. 2B).
A
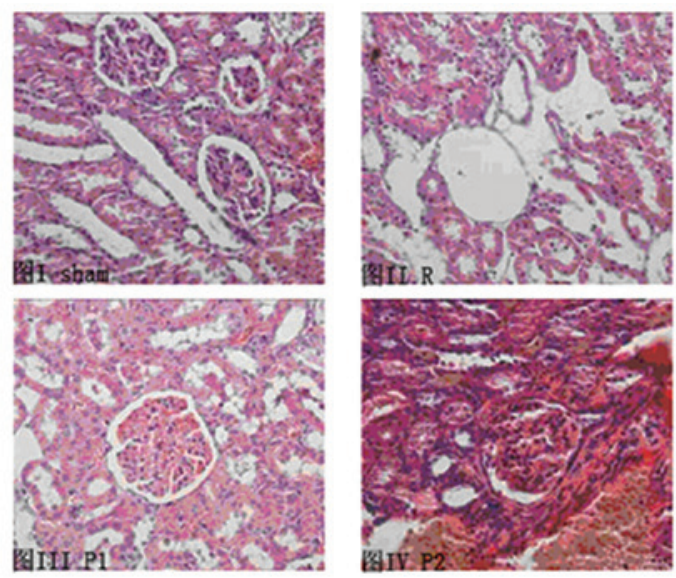

B
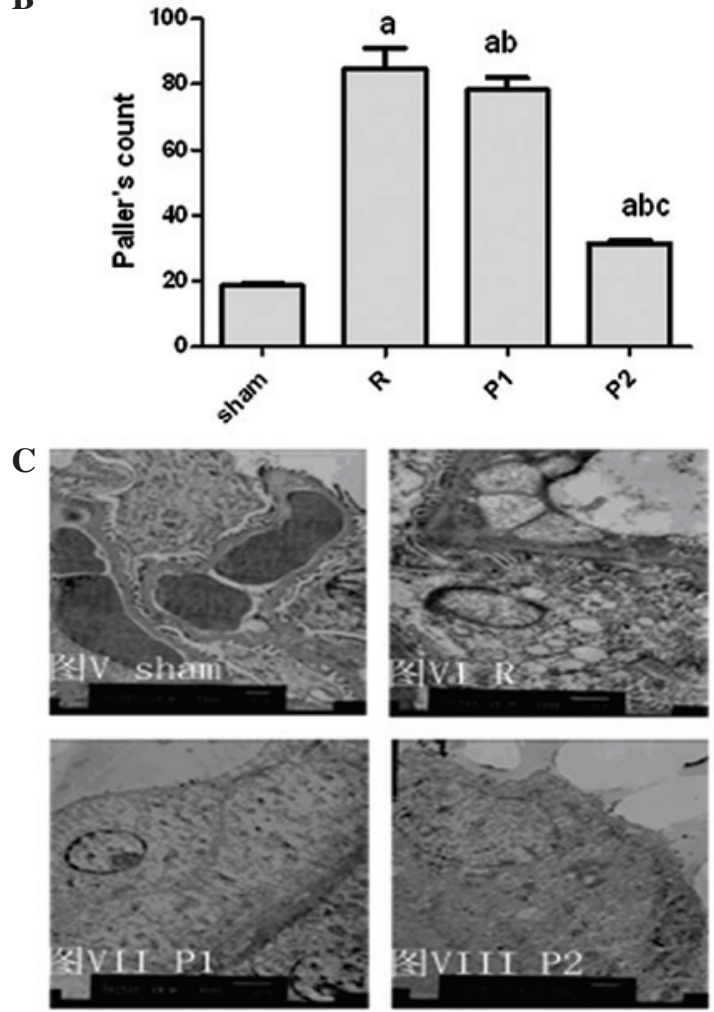

Figure 2. Tubular injury in propofol-treated ischemia/reperfusion injury (IRI) rats was significantly less compared with that observed in kidneys from untreated IRI rats. (A) Representative sections of the outer medulla from sham-operated, untreated IRI rats, rats treated with $5 \mathrm{mg} / \mathrm{kg}$ propofol and rats treated with $10 \mathrm{mg} / \mathrm{kg}$ propofol, three days after reperfusion (H\&E; magnification, $\mathrm{x} 400$ ). (B) Semiquantitative analysis of tubular damage in the kidneys of sham-operated rats, operated rats, rats treated with $5 \mathrm{mg} / \mathrm{kg}$ propofol and rats treated with $10 \mathrm{mg} / \mathrm{kg}$ propofol following reperfusion. Data are presented as mean \pm standard deviation (SD); $\mathrm{n}=8$ per group. ${ }^{\mathrm{a}} \mathrm{P}<0.05$ vs. $\mathrm{S} ;{ }^{\mathrm{b}} \mathrm{P}<0.05$ vs. $\mathrm{R} ;{ }^{\mathrm{C}} \mathrm{P}<0.05$ vs. $\mathrm{P} 1$. (C) Representative electron micrograph sections from sham-operated rats, operated rats, rats treated with $5 \mathrm{mg} / \mathrm{kg}$ propofol and rats treated with $10 \mathrm{mg} / \mathrm{kg}$ propofol three days after reperfusion. Original magnification, $x 7,200$. S, sham-operated rats; R, operated rats; P1, rats treated with $5 \mathrm{mg} / \mathrm{kg}$ propofol; $\mathrm{P} 2$, rats treated with $10 \mathrm{mg} / \mathrm{kg}$ propofol.

Morphological studies using electron microscopy demonstrated a certain degree of heterogeneous loss of brush border, bleb formation, cytoplasmic vacuolization, cellular necrosis, mitochondrial loss or disappearance, chromatin condensation and aggregation at the periphery of nuclei and nuclear fragmentation, and tubular luminal debris and obstruction in 


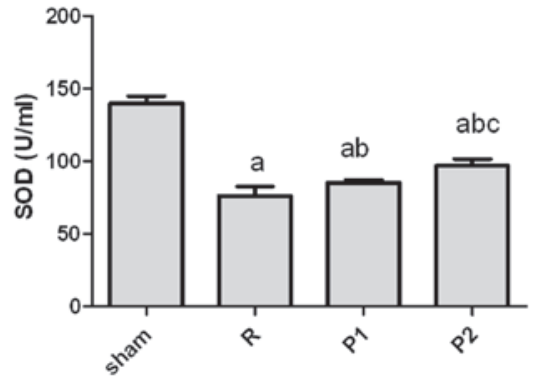

Figure 3. Superoxide dismutase (SOD) activity following ischemia/reperfusion injury (IRI). Data are presented as mean \pm standard deviation (SD); $n=8$ per group. ${ }^{a} \mathrm{P}<0.05$ vs. $\mathrm{S} ;{ }^{\mathrm{b}} \mathrm{P}<0.05$ vs. $\mathrm{R} ;{ }^{\mathrm{c}} \mathrm{P}<0.05$ vs. $\mathrm{P} 1$. S, sham-operated rats; $\mathrm{R}$, operated rats; $\mathrm{P} 1$, rats treated with $5 \mathrm{mg} / \mathrm{kg}$ propofol; $\mathrm{P} 2$, rats treated with $10 \mathrm{mg} / \mathrm{kg}$ propofol.

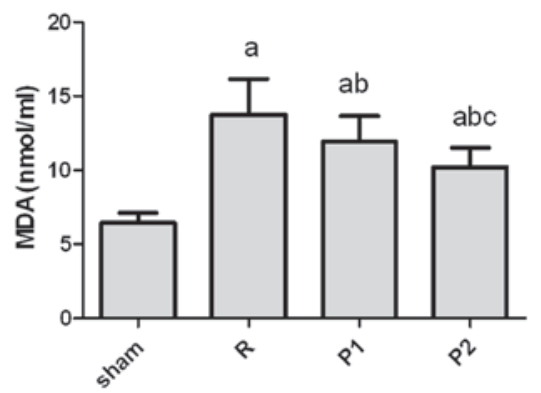

Figure 4. Lipid peroxidation following ischemia/reperfusion injury (IRI) Data are presented as mean \pm standard deviation (SD); $n=8$ per group. ${ }^{a} \mathrm{P}<0.05$ vs. $\mathrm{S} ;{ }^{b} \mathrm{P}<0.05$ vs. $\mathrm{R} ;{ }^{c} \mathrm{P}<0.05$ vs. $\mathrm{P} 1$. S, sham-operated rats; R, operated rats; $\mathrm{P} 1$, rats treated with $5 \mathrm{mg} / \mathrm{kg}$ propofol; $\mathrm{P} 2$, rats treated with $10 \mathrm{mg} / \mathrm{kg}$ propofol; MDA, malondialdehyde.

untreated kidneys. Damage was markedly reduced in propofoltreated kidneys (Fig. 2C).

Oxygen free radical scavenger SOD levels are increased in propofol-treated rats. Normally, tissues contain enough endogenous scavengers to protect against damage induced by oxygen free radicals (OFRs). The levels of SOD, one such scavenger, were measured following IRI. The SOD levels were significantly reduced following IRI compared with those in sham-operated controls (Fig. 3). Propofol-treated rats had significantly higher SOD levels compared with untreated rats following IRI (Fig. 3). Moreover, rats treated with $10 \mathrm{mg} / \mathrm{kg}$ propofol had significantly higher SOD levels compared with those treated with $5 \mathrm{mg} / \mathrm{kg}$ propofol (Fig. 3).

Lipid peroxidation by OFRs is reduced in propofol-treated rats. The effect of IRI on lipid peroxidation was evaluated in the rats. The lipid peroxidation by-product MDA was measured as a marker for membrane lipid peroxidation. IRI resulted in an increase in the whole kidney MDA levels of operated groups compared with that of the sham-operated group (Fig. 4).

Propofol-treated rats demonstrated less lipid peroxidation with significantly lower MDA levels compared with the untreated IRI controls. Rats treated with $10 \mathrm{mg} / \mathrm{kg}$ propofol had significantly lowere levels of MDA compared with those treated with $5 \mathrm{mg} / \mathrm{kg}$ propofol (Fig. 4).
A

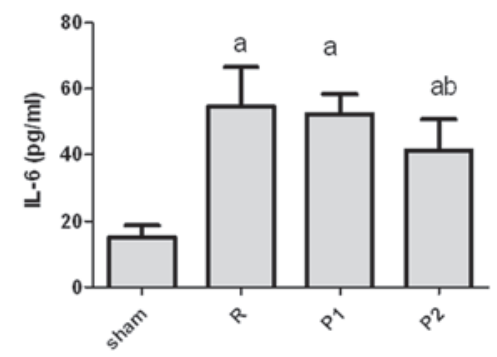

B

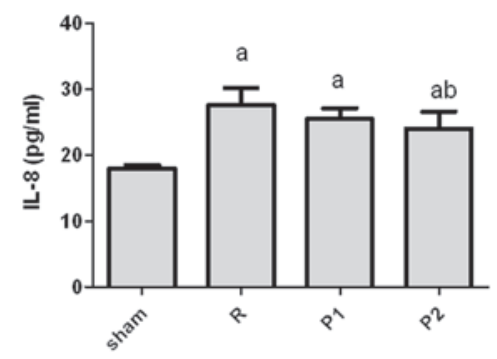

C

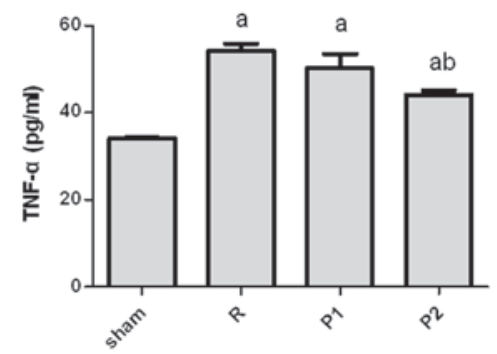

Figure 5. Effects of propofol on cytokine levels following ischemia/reperfusion injury (IRI). Levels of pro-inflammatory cytokines [interleukin (IL)-6, IL-8, and tumor necrosis factor (TNF)- $\alpha$ ] in the kidney were significantly reduced in $\mathrm{P} 1(5 \mathrm{mg} / \mathrm{kg})$ and $\mathrm{P} 2(10 \mathrm{mg} / \mathrm{kg})$ rats compared with controls following reperfusion. Data are presented as mean \pm standard deviation (SD); $n=8$ per group. ${ }^{a} \mathrm{P}<0.05$ vs. $\mathrm{S} ;{ }^{b} \mathrm{P}<0.05$ vs. R. $\mathrm{S}$, sham-operated rats; $\mathrm{R}$, operated rats; $\mathrm{P} 1$, rats treated with $5 \mathrm{mg} / \mathrm{kg}$ propofol; $\mathrm{P} 2$, rats treated with $10 \mathrm{mg} / \mathrm{kg}$ propofol.

Propofol attenuates pro-inflammatory cytokine expression in the kidney during IRI. To further determine the effects of propofol in the IRI kidney model, we examined the expression of cytokines (Fig. 5). IL-6, IL-8 and TNF- $\alpha$ levels were significantly increased in the IRI kidney compared with those in sham-operated controls. Cytokine levels increased in rats treated with $10 \mathrm{mg} / \mathrm{kg}$ propofol; however, the extent of the increase was much less than that in untreated IRI rats. No significant differences were identified between the two groups treated with different doses of propofol (Fig. 5).

Role of BMP2 in the kidney during IRI. To determine the role of BMP2 in our model, we measured mRNA expression levels of BMP2 in the kidney by real-time quantitative PCR. The level of BMP2 mRNA was significantly reduced following IRI compared with that in sham-operated controls (Fig. 6A and B). Sham-operated kidneys expressed abundant BMP2, whereas BMP2 mRNA expression decreased markedly in kidneys following IRI (Fig. 6A and B). By contrast, the reduction in mRNA expression for BMP2 was less in propofol-treated kidneys than in untreated kidneys (Fig. 6A and B).

Consistent with the real-time PCR data, western blots revealed that IRI induced a significant reduction in BMP2 expression in the kidneys of untreated IRI rats compared with 
A
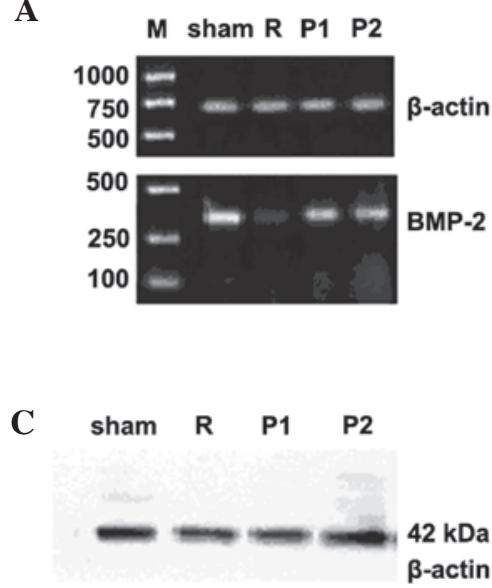

BMP-2

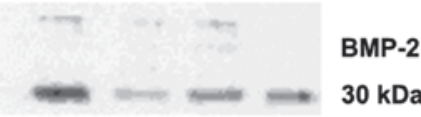

B

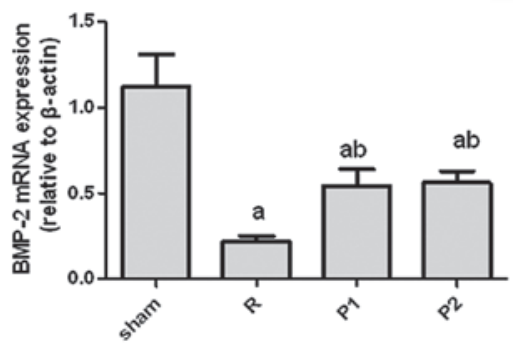

D

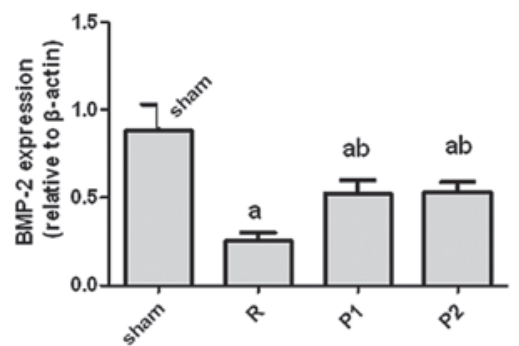

Figure 6. Bone morphogenetic protein 2 (BMP2) expression following ischemia/reperfusion injury (IRI). (A) BMP2 mRNA expression. (B) Quantitative reverse transcription-polymerase chain reaction (RT-PCR) analysis of BMP2 mRNA levels in the different groups. (C) Western blot analyses of BMP2 protein expression in the different groups. Representative results are shown. (D) The relative quantitation of BMP2 protein. S, sham-operated rats; R, operated rats; $\mathrm{P} 1$, rats treated with $5 \mathrm{mg} / \mathrm{kg}$ propofol; $\mathrm{P} 2$, rats treated with $10 \mathrm{mg} / \mathrm{kg}$ propofol. ${ }^{\mathrm{a}} \mathrm{P}<0.05 \mathrm{vs}$. $\mathrm{S}$; ${ }^{\text {b }} \mathrm{P}<0.05 \mathrm{vs}$. $\mathrm{R}$.

that in sham-operated controls (Fig. 6C and D). Downregulation of BMP2 expression following IRI was greatly attenuated in the propofol-treated rats.

\section{Discussion}

Previous experimental data suggests that IRI rapidly induces the formation of OFRs, while SOD levels are reduced in the kidneys following IRI $(20,21)$. In the present study we identified that IRI resulted in increased production of the lipid peroxidation by-product MDA in homogenates of whole kidneys. By contrast, propofol pretreatment reduced MDA levels, increased SOD levels and improved renal dysfunction following IRI. We identified that rats pretreated with propofol were protected from kidney dysfunction and histological damage. Protection was associated with a reduction in pro-inflammatory cytokine generation and a concomitant increase in BMP2 expression.

The most common cause of acute renal failure is renal ischemia, which causes functional impairment through a combination of renal vasoconstriction, tubular obstruction, tubular back-leakage of glomerular filtrate and reduced glomerular permeability (22). IRI results in the activation of multiple cell injury pathways that contribute to organ dysfunction, including those resulting in the production of OFRs (23).

OFRs are considered to cause cellular injury by attacking membranes through the peroxidation of polyunsaturated fatty acids $(24,25)$ during IRI. This lipid peroxidation results in increased membrane permeability in cells, mitochondria and lysosomes. Peroxidative injury of erythrocyte membranes has been reported to increase passive $\mathrm{K}^{+}$permeability with a loss of intracellular $\mathrm{K}^{+}$(26). Increased permeability of renal tubular cell membranes may lead to a loss of transport functions, whereas increased permeability of mitochondrial membranes impairs oxidative phosphorylation. Increased lysosomal permeability may result in the leakage of hydrolytic enzymes and acceleration of cellular degradation. In the current study, we identified that IRI increased the production of the lipid peroxidation by-product MDA in the homogenates of whole rat kidneys.

Propofol has been reported to modulate IRI, suggesting its potential for organ protection during surgery involving abdominal aortic clamping and possibly as a means for improving patient outcome (27). Propofol is a lipophilic hypnotic drug with proven antioxidant activity in in vitro and in vivo studies. This results in part from its chemical structure, which is similar to the natural antioxidant vitamin $\mathrm{E}(5,14)$. Propofol has been demonstrated to act as a scavenger of OFRs, reducing lipid peroxidation in the liver, kidney, heart and lung (28). It was reported that in an in vivo experimental model of reversible renal IRI, propofol anesthesia was associated with diminished neutrophil infiltration, and reductions in plasma pro-inflammatory cytokine levels, production of OFRs, lipid peroxidation and inducible nitric oxide synthase activity (29). Results from the study by Yuzbasioglu et al (30) demonstrated that IRI was significantly reduced in the presence of propofol and that the protective effects of propofol may be due to its antioxidant properties. Results from the study by Yuzer et al (31) demonstrated that IRI was significantly reduced in the presence of propofol and thiopental. The authors attributed the protective effects of these drugs to their antioxidant properties. In the current study, propofol pretreatment was observed to reduce lipid peroxidation, increase SOD levels and suppress the production of inflammatory cytokines.

BMPs are members of the TGF- $\beta 1$ superfamily and play important roles in diverse cell types. Vascular endothelial and smooth muscle cells express BMP receptors and secrete BMPs (30-32). Among them, BMP2 has been shown to regulate a host of cellular functions (33), including cardiovascular development, angiogenesis, neovascularization in tumors, vascular calcification and smooth muscle cell chemotaxis, in 
response to vascular injury $(34,35)$. It is considered that BMP signaling exerts important vasoprotective effects controlling the balance between proliferation and activation of apoptosis in endothelial and smooth muscle cells (36).

BMP2 is considered to signal primarily by activating the mothers against decapentaplegic (SMAD) and mitogen-activated protein kinase (MAPK) pathways (37), although evidence suggests that BMP2 may also activate nuclear factor $\kappa$-light-chain-enhancer of activated B cells (NF- $\kappa \mathrm{B})(38)$. The activation of BMP signaling, either by overexpression of BMP2 in vascular cells or administration of recombinant BMPs, results in endothelial dysfunction, oxidative stress and enhanced monocyte adhesiveness to the endothelium (39). BMP2 is selectively expressed by late outgrowth endothelial progenitor cells and plays a role in neoangiogenesis (40). Endothelial colony-forming cells (ECFCs) express BMP2 morphogens. BMP2 may be used as a marker of immaturity, the ECFC lineage and finally as an angiogenic marker during ECFC commitment and expansion. BMP-positive endothelial precursors correspond to ECFCs, responsible for neovascularization, whereas BMP-negative endothelial precursors correspond to proangiogenic hematopoietic progenitor cells (41). A previous study demonstrated that BMP2 is downregulated following IRI, which may contribute to an imbalance between cell proliferation and apoptosis, thereby causing renal injury (42). In the present study, propofol pretreatment was observed to promote BMP2 expression following IRI and may have contributed to neoangiogenesis, which may partly explain its renal protective effect. Future studies are required to elucidate the mechanism by which propofol regulates the expression of BMP2.

In conclusion, regulation of BMP2 levels may be an important mechanism for maintenance of cellular homeostasis. Propofol pretreatment exerts a protective effect in rats in an IRI model, which is partly correlated with upregulation of BMP2. This study may open new avenues of investigation into the antioxidant effects of propofol. An understanding of the mechanisms of action of propofol in IRI may introduce new therapeutic approaches not presently available.

\section{Acknowledgements}

This study was supported by the Doctor Fund Project of the Ministry of Education of China (project grant 20070159020) and the National Natural Science Foundation of China (81071503). The authors thank Medjaden Bioscience Ltd. for assisting in the preparation of this manuscript.

\section{References}

1. Bonventre JV and Zuk A: Ischemic acute renal failure: an inflammatory disease? Kidney Int 66: 480-485, 2004.

2. Thurman JM: Triggers of inflammation after renal ischemia/reperfusion. Clin Immunol 123: 7-13, 2007.

3. Ysebaert DK, De Greef KE, De Beuf A, et al: T cells as mediators in renal ischemia/reperfusion injury. Kidney Int 66: 491-496, 2004

4. Erdogan H, Fadillioglu E, Yagmurca M, Ucar M and Irmak MK: Protein oxidation and lipid peroxidation after renal ischemia-reperfusion injury: protective effects of erdosteine and N-acetylcysteine. Urol Res 34: 41-46, 2006.

5. Li XL, Zou XM, Gao P, Li YL, Wang H and Chen XW: Role of nitric oxide in ischemia-reperfusion injury and acute rejection in rat intestinal transplantation. Transplant Proc 40: 3342-3345, 2008.
6. Xia Z, Godin DV, Chang TK and Ansley DM: Dose-dependent protection of cardiac function by propofol during ischemia and early reperfusion in rats: effects on $15-\mathrm{F} 2 \mathrm{t}$-isoprostane formation. Can J Physiol Pharmacol 81: 14-21, 2003.

7. Javadov SA, Lim KH, Kerr PM, Suleiman MS, Angelini GD and Halestrap AP: Protection of hearts from reperfusion injury by propofol is associated with inhibition of the mitochondrial permeability transition. Cardiovasc Res 45: 360-369, 2000.

8. Kokita N, Hara A, Abiko Y, Arakawa J, Hashizume H and Namiki A: Propofol improves functional and metabolic recovery in ischemic reperfused isolated rat hearts. Anesth Analg 86: 252-258, 1998.

9. Yang CY, Wong CS, Yu CC, Luk HN and Lin CI: Propofol inhibits cardiac L-type calcium current in guinea pig ventricular myocytes. Anesthesiology 84: 626-635, 1996.

10. Zhou W, Fontenot HJ, Liu S and Kennedy RH: Modulation of cardiac calcium channels by propofol. Anesthesiology 86: 670-675, 1997.

11. Jordan JE,Zhao ZQ and Vinten-Johansen J: The role of neutrophils in myocardial ischemia-reperfusion injury. Cardiovasc Res 43: 860-878, 1999.

12. Simpson PJ, Fantone JC, Mickelson JK, Gallagher KP and Lucchesi BR: Identification of a time window for therapy to reduce experimental canine myocardial injury: suppression of neutrophil activation during 72 hours of reperfusion. Circ Res 63: 1070-1079, 1988.

13. Shin IW, Lim BW, Chung YS, et al: The effect of propofol on myocardial protection after regional ischemia-reperfusion injury in an in vivo rat heart model. Korean J Anesthesiol 55: 338-343, 2008.

14. Nauth A, Ristiniemi J, McKee MD and Schemitsch EH: Bone morphogenetic proteins in open fractures: past, present, and future. Injury 40 (Suppl 3): S27-S31, 2009.

15. El-Bizri N, Guignabert C, Wang L, et al: SM22alpha-targeted deletion of bone morphogenetic protein receptor $1 \mathrm{~A}$ in mice impairs cardiac and vascular development, and influences organogenesis. Development 135: 2981-2991, 2008.

16. Hansmann G, de Jesus Perez VA, Alastalo TP, et al: An antiproliferative BMP-2/PPARgamma/apoE axis in human and murine SMCs and its role in pulmonary hypertension. J Clin Invest 118: 1846-1857, 2008.

17. Wybenga DR, Di Giorgio J and Pileggi VJ: Manual and automated methods for urea nitrogen measurement in whole serum. Clin Chem 17: 891-895, 1971.

18. Kueltzo LA, Ersoy B, Ralston JP and Middaugh CR: Derivative absorbance spectroscopy and protein phase diagrams as tools for comprehensive protein characterization: a bGCSF case study. J Pharm Sci 92: 1805-1820, 2003.

19. Paller MS, Hoidal JR and Ferris TF: Oxygen free radicals in ischemic acute renal failure in the rat. J Clin Invest 74: 1156-1164, 1984.

20. Morsy MD, Mostafa OA and Hassan WN: A potential protective effect of alpha-tocopherol on vascular complication in spinal cord reperfusion injury in rats. J Biomed Sci 17: 55, 2010.

21. Sasaki M and Joh T: Oxidative stress and ischemia-reperfusion injury in gastrointestinal tract and antioxidant, protective agents. J Clin Biochem Nutr 40: 1-12, 2007.

22. van der Heijden $M$, Versteilen AM, Sipkema $P$, van Nieuw Amerongen GP, Musters RJ and Groeneveld AB: Rho-kinase-dependent F-actin rearrangement is involved in the inhibition of PI3-kinase/Akt during ischemia-reperfusion-induced endothelial cell apoptosis. Apoptosis 13: 404-412, 2008.

23. Bayrak O, Turgut F, Karatas OF, et al: Oral beta-glucan protects kidney against ischemia/reperfusion injury in rats. Am J Nephrol 28: 190-196, 2008.

24. Schramm L, Weierich T, Heldbreder E, Zimmermann J, Netzer $\mathrm{KO}$ and Wanner C: Endotoxin-induced acute renal failure in rats: effects of L-arginine and nitric oxide synthase inhibition on renal function. J Nephrol 18: 374-381, 2005.

25. Spek CA, Brüggemann LW and Borensztajn KS: Protease-activated receptor 2 blocking peptide counteracts endotoxin-induced inflammation and coagulation and ameliorates renal fibrin deposition in a rat model of acute renal failure. Shock 33: 339; author reply 339-340, 2010.

26. Petronijević ND, Mićić DV, Duricić B, Marinković D and Paunović VR: Substrate kinetics of erythrocyte membrane $\mathrm{Na}, \mathrm{K}-\mathrm{ATPa}$ e and lipid peroxides in schizophrenia. Prog Neuropsychopharmacol Biol Psychiatry 27: 431-440, 2003.

27. Kato R and Foëx P: Myocardial protection by anesthetic agents against ischemia-reperfusion injury: an update for anesthesiologists. Can J Anaesth 49: 777-791, 2002. 
28. Jin YC, Kim W, Ha YM, et al: Propofol limits rat myocardial ischemia and reperfusion injury with an associated reduction in apoptotic cell death in vivo. Vascul Pharmacol 50: 71-77, 2009.

29. Sánchez-Conde P, Rodriguez-López JM, Nicolás JL, et al: The comparative abilities of propofol and sevoflurane to modulate inflammation and oxidative stress in the kidney after aortic cross-clamping. Anesth Analg 106: 371-378, 2008.

30. Yuzbasioglu MF, Aykas A, Kurutas EB and Sahinkanat T: Protective effects of propofol against ischemia/reperfusion injury in rat kidneys. Ren Fail 32: 578-583, 2010.

31. Yuzer H, Yuzbasioglu MF, Ciralik H, et al: Effects of intravenous anesthetics on renal ischemia/reperfusion injury. Ren Fail 31: 290-296, 2009.

32. Dhore CR, Cleutjens JP, Lutgens E, et al: Differential expression of bone matrix regulatory proteins in human atherosclerotic plaques. Arterioscler Thromb Vasc Biol 21: 1998-2003, 2001.

33. Sorescu GP, Song H, Tressel SL, et al: Bone morphogenic protein 4 produced in endothelial cells by oscillatory shear stress induces monocyte adhesion by stimulating reactive oxygen species production from a nox1-based NADPH oxidase. Circ Res 95 773-779, 2004

34. Shin V,Zebboudj AF and Boström K: Endothelial cells modulate osteogenesis in calcifying vascular cells. J Vasc Res 41: 193-201, 2004.

35. Sorescu GP, Sykes M, Weiss D, et al: Bone morphogenic protein 4 produced in endothelial cells by oscillatory shear stress stimulates an inflammatory response. J Biol Chem 278 : $31128-31135,2003$.
36. Abe J: Bone morphogenetic protein (BMP) family, SMAD signaling and Id helix-loop-helix proteins in the vasculature: the continuous mystery of BMPs pleiotropic effects. J Mol Cell Cardiol 41: 4-7, 2006.

37. Csiszar A, Lehoux S and Ungvari Z: Hemodynamic forces, vascular oxidative stress, and regulation of BMP-2/4 expression. Antioxid Redox Signal 11: 1683-1697, 2009.

38. Ten Dijke P, Goumans MJ, Itoh F and Itoh S: Regulation of cell proliferation by Smad proteins. J Cell Physiol 191: 1-16, 2002

39. Funaki C, Hodges RR and Dartt DA: Role of cAMP inhibition of p44/p42 mitogen-activated protein kinase in potentiation of protein secretion in rat lacrimal gland. Am J Physiol Cell Physiol 293: C1551-C1560, 2007.

40. Csiszar A, Ahmad M, Smith KE, et al: Bone morphogenetic protein-2 induces proinflammatory endothelial phenotype. Am J Pathol 168: 629-638, 2006.

41. Csiszar A, Smith KE, Koller A, Kaley G, Edwards JG and Ungvari Z: Regulation of bone morphogenetic protein-2 expression in endothelial cells: role of nuclear factor-kappaB activation by tumor necrosis factor-alpha, $\mathrm{H}_{2} \mathrm{O}_{2}$, and high intravascular pressure. Circulation 111: 2364-2372, 2005.

42. Yang YL, Ju HZ, Liu SF, et al: BMP-2 suppresses renal interstitial fibrosis by regulating epithelial-mesenchymal transition. J Cell Biochem 112: 2558-2565, 2011. 